nor large doses of the iodide of potassium in syphilis, nor colchicum in gout.

I have now treated over sixty cases of acute articular rheumatism in the Infirmary here since salicine has come into use. In no case has there been any severely unpleasant result, nor long delay in defervescence and subsidence of pain and swelling. Careful watching is the chief thing required ; and this is the reason that the remedy has gained so much greater repute in hospital than in private practice. Relapses will occur if the remedy be left off, or even reduced in quantity, too soon. In such a case, full doses should be resumed immediately. There is, in most cases, great anæmia left to contend with, requiring iron as well as quinine for its cure. Without now entering into statistics, I can feel assured that the stay in hospital has been greatly less here under the treatment of the salicylates, than under the potash or any other former mode of cure.

\section{ANTISEPTIC SURGERY.}

By WILliaM MAIN, M.D., New Ferry, Birkenhead.

THE cause of the occasional failures in antiseptic surgery is often very obscure. A short time ago, I assisted in a case of amputation of the breast, where the operator-an experienced hospital surgeon who habitually uses the antiseptic method-took every possible care in his arrangements; yet, on the third day, a blush on several parts of the wound warned us too surely of the presence of septic germs; and, as we expected, the wound then began to suppurate, and did so as freely as if no precautions whatever had been taken to prevent it. This disappointment made me reflect on the possible cause of failure in this, and uccasionally in other carefully managed operations.

When reasoning on antiseptic surgery, we must constantly bear in mind the well known experiments of Professor Lister and Mr. Tyndall. In the hands of the former, as will be remembered, the urine, in the Florence flask with the depressed spiral tube, remained clear and sweet, and, I rather think, continues in the same state at the present day; while that in the flask with the straight upright stem became turbid and putrid in a few days. Mr. Tyndall, again, arrived at the same result, but in a different way. He allowed a dust-tight box to remain completely at rest till all the dust-particles had settled, as was proved by a transmitted beam of light being no longer visible. He then carefully introduced vegetable infusions, which remained clear and sweet in the box, while they decomposed rapidly when exposed to ordinary air.

With these facts before us, it occurred to me that, though the method of operating under carbolic spray very generally prevents septic effects, yet there can be no doubt that it occasionally fails where every known precaution has been taken; and, in the many cases where it succeeds, the good results may be effected in one of two ways, or by a combination of both. First, the carbolic acid in the spray may destroy the vitality of the septic germs by contact in the air; or, secondly, the particles of spray may attach themselves to the germ-particles in the air, and, when the spray-stream is properly directed, carry them over the wound, and thus filter or sweep the air, as it were, around; or, thirdly, the spray may, if so directed, sweep down the germ-particles in and upon the wound, where they may become destroyed by the carbolic lotion. In order to test the vitality of bacteria in carbolic acid, I put two drachms of decomposing urine, full of these interesting creatures, into an ounce of carbolic lotion of the strength of $\mathbf{I}$ to 80 and other two drachms of the same urine into lotion of the strength of I to 40. After twenty-four hours, I found these little creatures as active and lively as ever in both solutions. The result of this experiment, and the mysterious failure in some carefully conducted cases, make me suspect that carbolic spray during an operation may probably act beneficially, not by killing the septic germs, but rather by sweeping these germs from the air, and carrying them away from the wound. When we recall the results of experiments, this modus operandi would appear to be quite possible, if not even probable; and further, may not some of the mysterious failures have been owing to the spray having been directed at and not over the wound, which wou!d in this case become crowded by septic germs? and we have just seen that bacteria, at any rate, are not always killed by contact with carbolic lotion. Should this reasoning not impress others as it does me, I trust that surgeons may at least have some regard to this point, and try the results of a non-poisonous spray, instead of the carbolic lotion commonly used. For this purpose, I would suggest a mixture of glycerine and water. When these are mixed in the proportion of $I$ to $\mathbf{I} 6$, I find the specific gravity is 20 above that of water; so that, if such a lotion were sprayed across or over, and not at a wound, the result, I trust, may be even more successful than carbolic lotion has proved to be. In any case, it is worth a trial, as the result would be interesting.

I am not aware if Professor Lister brought forward the direction of the spray as a possible source of success or failure in antisep ic surgery; but, if he did so, certainly at the present time it is not in the least attended to.

\section{CLINICAL MEMORANDA.}

\section{AN UBIQUITOUS POISON.}

IN relation to the article in the JOURNAL of November $26 t \mathrm{~h}$, upon lead-poisoning, the following case may be of some interest. A dressmaker, aged 30, who was attending at the Leeds Dispensary, was found to have a distinct blue line upon the gums. Under potassium-iodide, this line disappeared in a few weeks or months (the paper showing the precise dates is lost). It was impossible at first to discover any source of lead-poisoning, though inquiries were made about, as it seemed, every article likely to furnish lead ; the other symptoms-furred tongue, constipation, general debility, a peculiar inflammation with œdema of the lips, slight wasting in a woman naturally very thin-did not then appear decisive, and $I$ was beginning to think that the blue line must have been caused in some other way, when I accidentally learned from a merchant that silken thread, being sold by weight and not by length, is sometimes adulterated with sugar of lead. Upon now questioning the patient, she informed me that it had been a common practice with her, when at work, to hold silk (and also other kinds of thread) in her mouth, and that she had done this the more readily with silk, inasmuch as it often had a sweet taste.

Upon further inquiry, I learn that it is well known that the silk thread of the best makers is tasteless, whereas some inferior thread is sweet. My informants did not themselves know the reason of this difference. T. Churton, M.D., Leeds.

\section{RAPID RECURRENCE OF MEASLES.}

ON November 3 rd, I was called to attend Robert C., aged between three and four years, and found him suffering from a mild attack of the measles. Though rather more prostrated than one might have expected from the mild nature of the attack, he soon recovered, and my attendance did not extend over a very few days. On the evening of December 6th, I was again called to him, and found him covered from head to foot with a well developed rash of measles.

The boy's mother told me he had got quite better from the first attack, and was well up to a day or two before, when he commenced to sicken, and that on the previous day this rash had commenced coming out. A younger child was also pointed out to me in whom the rash was just dying away after a short illness, for which, there being no severe symptoms, medical advice had not been sought.

I never heard of a second attack so soon after the first ; and a brother practitioner, older than myself, tells me he never did: hence I thought this case might perhaps be worthy of record. I have only to add that, in both the attacks, all the usual symptoms were present ; and that the father (a sweep) is a miserably poor man inhabiting a wretched dirty little hovel with his family, and that cleanliness, comfort, and proper food are unfortunately but too little known to them.

J. J. Byrne, Preston.

\section{OBSTETRIC MEMORANDA.}

\section{THE TREATMENT OF POST PARTUM HAMORRHAGE.}

THERE can be no situation of greater gravity than a delivery followed by flooding; no occasion on which the practical skill of the medical attendant will be more called on than to decide there and then what is the best thing to do. It behoves us then to review from time to time the resources with which to combat this alarming complication, and to determine, as far as may be, what course to follow when placed face to face with it.

The injection of the perchloride of iron, as recommended by Kiwisch and Barnes, is a form of treatment which many hesitate to adopt. The fear of the remedy proving ultimately as disastrous as the hæmorrhage, no doubt often prevents it from being applied; still it is one of our most powerful styptics, and, all other methods having failed, no one would be justified in not using it; the eminently successful cases lately recorded by Drs. Belfield and Steel testify to its great value. Dr. Atthill of Dublin has given us a valuable aid-the injection of hot water; free from danger, it stimulates the uterus, and seldem fails to 